Revista Iberoamericana, Vol. LXX, Núms. 208-209, Julio-Diciembre 2004, 1031-1041

\title{
CONOCIMIENTO SUPLEMENTARIO: QUEERING EL EJE NORTE/SUR
}

\author{
POR \\ Francine Masiello \\ University of California, Berkeley
}

El género y la sexualidad han sido los hitos-guía de la crítica cultural; son tan necesarios para el estudio del arte y la literatura como lo han sido para las revisiones postmarxistas de la historia de la lucha de clases. Sin embargo, desde una perspectiva latinoamericana, estas líneas de cuestionamiento cumplen también otra función en tanto que son mediadoras de la circulación cultural que se desplaza de Norte a Sur. En particular, género y sexualidad interrumpen la uniformidad del "flujo” Norte/Sur e introducen formas desconocidas de ruptura en la lógica del “sentido común” de la globalización. Con razón entonces, no hace mucho tiempo que hemos empezado a examinar de manera apropiada las rutas a través de las cuales se desplazan estos debates; no sólo examinamos de qué manera las teorías anglo europeas del género ingresan a Latinoamérica para estructurar los debates locales, sino también, los modos en que América Latina responde a la teoría del Norte.

Mi intención inicial fue idear una investigación acerca de los modos en que estas preguntas sobre el género y la identidad sexual viajan de Norte a Sur a través de importantes publicaciones culturales. Esto traza un camino a través del Feminaria de Lea Fletcher en Argentina o del proyecto académico de Mora en la Universidad de Buenos Aires; la Revista de crítica cultural de Nelly Richard, o Nomadías de la Universidad de Chile; la revista de Estudos feministas en Brasil, o Fem y Debate Feminista en México. Estas publicaciones son los puntos de partida lógicos para rastrear el impacto de las intervenciones del género en la crítica cultural. No sólo introducen osados paradigmas para la circulación del conocimiento, sino que también construyen modelos alternativos para considerar la política y la cultura nacional. ${ }^{1}$ Pero aquí quiero tomar una dirección diferente, un curso menos obvio en el eje Norte/Sur, moviéndome en un espacio que presente un desafío tanto para las academias como para aquellos postulados establecidos por la teoría universal. Mi foco de interés es el periodismo cultural para mujeres que surge de la prensa popular.

Más específicamente aún, quiero referirme a los estilos de compromiso que propone LAS/12, el suplemento feminista del diario argentino Página/12. Parte de la prensa

\footnotetext{
${ }^{1}$ He consignado las amplias implicaciones del periodismo cultural hecho por mujeres en "El género de la democracia”. La cultura de un siglo: América Latina en sus revistas. Comp. Saúl Sosnowski. Buenos Aires: Alianza, 1999. 537-48.
} 
sensacionalista opositora basada en la retórica de la sátira, Página/12 ha producido algunas de las críticas más agudas a las fallas del proceso democrático. Su humor cáustico y escandaloso, como lo ha llamado el crítico Horacio González, ha forjado nuevas identidades sociales a despecho del estado. ${ }^{2}$ Pero, de no ser por las historias de quién se acuesta con quién, o qué vedette ha sido relacionada con qué ministro, el problema del género no ha ingresado al horizonte de sus editores ni sus corresponsales; tampoco los intereses políticos de las mujeres han logrado ninguna atención seria. No obstante, en abril de 1998, apareció una página para mujeres, probablemente orientada a satisfacer la necesidad del diario de ampliar su mercado de consumidores; esta aparición del suplemento coincidió también con el ascenso político de Graciela Fernández Meijide. Aun así, la página para mujeres va bastante más allá que los suplementos habituales. A diferencia de la sección principal de Página/12, que lanza sus ataques satíricos contra el gobierno y sus funcionarios, el suplemento para mujeres dirige su mirada hacia las construcciones de género que realiza el mercado y las permanentes luchas del estado y el mercado para limitar la subjetividad. Más recientemente, el suplemento ha arremetido contra los mitos de la masculinidad que subyacen en el fervor nacionalista; ha ofrecido la posibilidad de analizar las crisis nacionales desde la perspectiva del género. En este sentido, LAS/12 -tal es el nombre del suplemento-, bien podría ser considerado una de las expresiones más radicales del género para enfrentar no sólo la crisis económica en la Argentina, sino también el fenómeno más amplio del neoliberalismo y la globalización. Señala desde una perspectiva editorial crítica no sólo temas como la identidad sexual y los roles asignados a las mujeres, sino, también, la inclusión de las mujeres en la circulación de productos culturales. Entre las colaboradoras cuya aguda mirada ha dirigido este proyecto está la presencia de María Moreno.

Una de las sagaces feministas de América Latina con una extensa carrera en el periodismo, María Moreno, ha trazado parámetros de investigación que son decididamente no académicos; su discurso consistentemente se ha dirigido a un público masivo que puede ser seducido por lecturas heterodoxas. Ampliamente considerada como una de las críticas más sorprendentes de Argentina, Moreno es una disidente en el campo cultural, una posmoderna de vanguardia, que resiste tanto el exagerado academicismo como las teorías habituales de género. De este modo, ha armado su carrera con los diversos elementos del periodismo free lance (desde tiempos de su colaboración en La Opinión) y a través de la producción de textos creativos que desobedecen tanto a la ley del género como a la de los géneros literarios (ver, por ejemplo, su texto híbrido, El Affair Skeffington, 1992; o su crónica sobre un delincuente del otro fin de siglo, El petiso orejudo, 1994).

El suplemento, donde la voz de Moreno ejerce un feroz y penetrante comentario sobre la cultura y la política de nuestros tiempos, se pregunta de qué modo puede surgir un marco teórico para el feminismo desde el campo de los medios masivos: cómo convocar un público, cómo interpelar la diferencia, cómo organizar la teoría desde un espacio periodístico sin ahuyentar a los lectores no entrenados. Cómo ir más allá del primer feminismo militante para alcanzar una audiencia no tan convencida por el dogmatismo feminista como cautivada por las ofertas que el mercado neoliberal les pone al alcance de

\footnotetext{
${ }^{2}$ Ver Horacio González: La realidad satírica: 12 hipótesis sobre Página12.
} 
la mano. Como espero demostrar aquí, LAS/12 y en particular el ojo inteligente de María Moreno nos conmina a que miremos el modo en que la metrópolis modela el deseo del Sur y las respuesta que el Sur ofrece al Norte.

Desde el comienzo, Moreno y sus colegas juegan con temas y objetos que supuestamente constituyen “el interés de las mujeres”, para exponer las condiciones opresivas que los mismos generan al crear una ilusión de libertad para las mujeres. La moda y el cine, los dilemas de madres y esposas, la búsqueda continua de la tranquilidad doméstica, aquellas pequeñas “ayudas” psicológicas que, como se sabe, pretenden otorgar a la mujer un renovado impulso en la vida, se cuentan entre los temas de los suplementos para mujeres en casi todas partes del mundo. Pero Moreno los invierte. Parece demostrar que mientras algunas de estas cuestiones son obvias (y omnipresentes) en aquellas secciones del suplemento que se ocupan del automejoramiento de las mujeres, las respuestas que ofrecen son, también, predecibles: casi antes de leer el suplemento sabemos cuál será el consejo que se dará a las mujeres. De hecho, ésta es una de las mayores críticas que puede hacerse a los suplementos como forma cultural para las masas; incluso, muchos de quienes los apoyan expresan esta reserva. Con respecto a esto, y citando a Dora Codelesky, una activista en favor del aborto, las editoras finalmente advierten: "los espacios dedicados a la mujer son importantes porque sirven para hacer 'más ignominiosa la ignominia’ conociéndola. Más opresiva la opresión, publicándola” (5 de marzo de 1999). Moreno habla desde dentro de la boca del monstruo: deconstruye los hábitos del consumismo femenino desde el centro mismo de la escena de una publicación que debe sobrevivir a través de la publicidad y las ventas.

Moreno también modifica la disposición de un público lector ansioso por encontrar respuestas a las preguntas convencionales, expandiendo los límites de la imaginación femenina y saboteando las ideas habituales acerca del lugar de las mujeres en el mundo. LAS/12 se pone así a la altura del desafío de Moreno y presenta esta paradoja en letras de molde. Las colaboradoras manipulan la construcción tradicional de género, así como el estatuto de la columna convencional para mujeres que han facilitado estas representaciones. “La mujer no es un suplemento" escriben juguetonamente, tomando las palabras de Magui Bellotti, abogada y activista feminista (5 de marzo de 1999). Tampoco es el suplemento LAS/12 nada suplementario en ninguno de los sentidos habituales. Esta inversión se manifiesta en el alcance de los temas que, subrepticiamente, ingresan a las páginas de $L A S$ / 12. Las descripciones de artefactos para el hogar y de productos de baño permiten a las editoras referirse a las teorías de la sexualidad femenina, los derechos civiles y las demandas feministas por la liberación del trabajo doméstico. Las entrevistas a celebridades de Hollywood y las discusiones sobre el arte posmoderno les permiten estudiar el proceso discursivo que "produce" una ilusión de mujer.

En un movimiento para globalizar los intereses del suplemento, Hollywood, París o las galerías de arte de Nueva York aparecen con frecuencia en el horizonte de la publicación. Pero las editoras también hacen observaciones sobre los fracasos de la cultura estadounidense. Por ejemplo, LAS/12 se detiene en las violaciones a los derechos humanos de las mujeres prisioneras en los Estados Unidos, denunciando la tortura física ejercida sobre las internas; la representación de las mujeres de origen hispanoamericano en las películas de Hollywood; la cultura del cocktail de los suburbios estadounidenses que se 
hace evidente en las publicidades de los famosos y, más recientemente, el papel que juegan las mujeres estadounidenses que se oponen a los esfuerzos bélicos de George W. Bush. Estos ensayos nos recuerdan que la mirada del sur está siempre alerta a la cultura del norte, pero no simplemente con el propósito de convertirse en una copia servil, sino para señalar la injusticia mundial. En el proceso, la natural autoridad del Norte se torna desconocida a la luz de los pormenores del género, limitando los circuitos del deseo que el suplemento pretende sostener y vender.

Igualmente importante es el terreno de la teoría que subyace en la cobertura de estrellas y celebridades. LAS/12 dedica una generosa atención a la construcción del personaje femenino, a las normas que separan la vida pública y la privada, a los recursos extraídos de la teoría psicoanalítica que ubican al sujeto femenino en el mundo y se arrogan el derecho de explicar su intelecto y su psiquis. Con razón, entonces, las editoras de LAS/ 12 revelan las limitaciones de la teoría lacaniana (la terapia de mayor consumo en Argentina) y surcan las aguas de psicologías alternativas y populares que conectan la atención de las mujeres norteamericanas y sudamericanas. Enfoques new age, fantasías eróticas, debates sobre la capacidad orgásmica de las mujeres pueden parecer materia editorial de las superficiales revistas tradicionales (en Estados Unidos, pensamos en Cosmopolitan o, en una versión más tediosa y puritana, la Ladies’ Home Journal), pero cuando $L A S / 12$ se refiere a estos temas, aspira a algo más: a socavar las premisas mismas de la cultura de masas que reclama para sí la autoridad interpretativa sobre las mujeres. No se trata simplemente de introducir las teorías que concitan la atención femenina, sino de mostrar el modo en que estas filosofías se las arreglan para mantener cautivas a las mujeres. Por ejemplo, Moira Soto, una de las colaboradoras habituales de $L A S / 12$, se pregunta por el destino de las divas y vuelve al concepto de star system que hace estragos en la vida personal de las mujeres célebres (su reciente interés por Marilyn Monroe, insiste, por cierto, en este rasgo). La glamorosa estrella de cine de los años cuarenta y cincuenta, que aunaba el personaje público y la vida privada, hoy está cuestionada. Soto indaga cómo es creada y sostenida la aspirante a estrella, cómo la maquinaria cinematográfica crea el aura del arquetipo. En síntesis, Soto advierte de qué modo los peinados, las poses, el fumar y el estilo de vestir contribuyen a una ilusión de belleza sin tacha y construyen un vínculo aparentemente indisoluble entre el trabajo y la vida privada de la diva.

La teoría ingresa al suplemento a hurtadillas, dispersa en entrevistas a figuras célebres, a través de personalidades, incorporada por un nombre. Así, LAS/12 pone en juego la voz contra el personaje público, la historia de vida contra la imagen congelada. Moreno pasa de las instantáneas de vida al movimiento activo, separando la imagen pública de la persona que piensa, para alcanzar el sentido subyacente de la perspectiva feminista que puedan defender figuras prominentes. Una entrevista con María Elena Walsh se refiere a las limitaciones de la mujer en la política argentina; otra con Griselda Gambaro consigna los poderes del lazo homosocial que excluye a las mujeres del debate público; un encuentro con Erica Jong es el pretexto para hablar sobre las identidades de las minorías, sobre el holocausto y la supervivencia. Una nota sobre la biografía de Coco Chanel y otra acerca de Carolina Herrera abren la reflexión sobre las imposiciones de la moda sobre el cuerpo femenino de vanguardia. Y el estrafalario vestido de Martirio, la cantante pop española, se explica como una iniciativa posmoderna de autoconstrucción 
femenina. Imágenes de Jodie Foster y Madonna, Grace Kelly y Nicole Kidman se incorporan a discusiones varias que nos recuerdan el artificio de representación en las descripciones de los temas femeninos. Este es el principio de una extensa investigación acerca de los mecanismos de seducción consumista que silencian las voces desobedientes y promueven el control de los signos de la diferencia.

En las páginas del suplemento, el cine, el diseño de ropa y el negocio de la música popular son ofertas habituales, disponibles para las mujeres con el fin de alentar el apetito de los consumidores. Con todo, en sus críticas, Moreno y sus colegas siempre se ubican un paso atrás de la celebración consumista con el fin de recordar a los lectores el papel que el mercado juega en formar tanto nuestro gusto como nuestros valores. Por un lado, las escritoras de $L A S / 12$ confeccionan imágenes comunes de mujeres y las ponen a disposición para que el lector las consuma; por el otro, nos obligan a pensar de qué modo el deseo es organizado por estrategias de publicidad y de mercado. Esta trayectoria en zig-zag por las fronteras de la inteligibilidad es un movimiento continuo de las perspectivas de la cultura: alto y bajo, privado y público, pesado y liviano, como categorías críticas, se mezclan con el fin de desmontar el sentido de "mujer" tal como ha sido proyectado desde los medios masivos y la teoría académica.

Podría incluso decirse que la teoría funciona como una conjunción de mapas, yuxtaponiendo una crítica de los espacios geopolíticos con una crítica a los sistemas de escritura en los que éstos se inscriben. ${ }^{3}$ Así, el suplemento feminista insiste en una simultaneidad paradójica ya que desarticula los productos culturales que los editores deben apoyar. Más importante aún, de manera amena, el suplemento avala los proyectos regidos por el mercado y, al mismo tiempo, fija la identidad de los consumidores en la escena de la diferencia. Esta dualidad atraviesa $L A S / 12$ y es parte constitutiva de la forma periodística en sí misma, una capacidad para el "tira y afloje” que teoriza sin remitir al aparato teórico formal. El activismo es el objetivo y se fundamenta en la mención de sistemas que dependen menos de los dichos de la teoría posestructuralista que de las voces de la comunidad local.

No pretendo ser irónica si digo que, desde las páginas de Página12, el suplemento fuerza el derrumbe de lo público y lo privado y de sus esferas habituales de significado. Por ejemplo, el baño, el dormitorio o la cocina se convierten en el centro de muchos ensayos periodísticos: el dormitorio es un pretexto para repensar de qué modo el mobiliario funciona como mediador de los deseos sexuales y los sueños; el baño se presenta como un espacio en el que circulan productos internacionales que sirven como adorno y decoración, más allá del uso que prestan a las necesidades corporales privadas. Y aunque la cocina se erige como el lugar idóneo para la conversación íntima, es también el sitio donde se desata la violencia neoliberal, explican las periodistas, el lugar donde los bienes de consumo ingresan para alterar la paz del hogar; es descripta, además, como el lugar en el que se realizan los abortos inseguros e ilegales, donde los inadecuados programas sociales del estado son confrontados con las necesidades insatisfechas de las mujeres. La convergencia de estos mundos conflictivos no nos lleva de vuelta a la teoría

\footnotetext{
${ }^{3}$ Esta es una teoría que Henri Lefebvre ha hecho circular en The Production of Space. Oxford: Blackwell, 1991.
} 
del espacio público y privado del tipo de las que ensayaron teóricas feministas como Shelly Rosaldo y Louise Lamphere y, más tarde, Nancy Fraser; en lugar de eso, la intersección de planos, por lo general separados, sirve para reflejar los impulsos eróticos en constante movimiento, los que coexisten más allá del estado y de la ley.

En todo esto observamos la traducción de los cuerpos a través de cambiantes estilos de autorrepresentación: a través de la casa y la calle, a través de la mirada sobre las celebridades internacionales, a través del examen de las estrategias de los medios que crean a las mujeres como público lector. Esto, por supuesto, exige el cuestionamiento de las relaciones entre género y traducción, y de las prácticas interpretativas que modifican la representación de la mujer de una cultura a otra.

La traducción es un tema subyacente: cómo pasan de una lengua a otra los materiales de la teoría cultural, cómo puede releerse el aura de las celebridades de la pantalla desde los márgenes del sur, cómo se resemantiza la sexualidad al cruzar las fronteras de la casa y el estado. En este contexto, la celebración del 50 aniversario de la publicación de El Segundo Sexo, provocó no sólo una nueva revisión de Simone de Beauvoir, sino también un llamado de atención para considerar las estrategias de traducción que, en todo el mundo, han alterado su reconocido libro. Moreno advierte, citando a Sylvie Chaperon, cómo fue truncado el texto al pasar a los sistemas de las distintas lenguas: en Japón, la palabra "femineidad” fue sustituida por "maternidad”; en los Estados Unidos, la traducción al inglés de El Segundo Sexo fue simplificada para eliminar lecturas complejas; en la Unión Soviética, el texto estuvo prohibido hasta los tiempos de la Glasnost; en Argentina, el ingreso de El Segundo Sexo no tuvo el propósito de crear una estallido público, sino el de proporcionar el registro de una confesión única e individual, la autorrevelación de un individuo destacado. Más allá de los abordajes más convencionales, la traducción funciona como un marco de recepción de segundo grado de una fuente extranjera que indica la conciencia política y el accionar colectivo de la comunidad locales. El objetivo de las editoras de $L A S / 12$ es recordarnos la pérdida de una narrativa emancipadora cuyas iniciativas militantes han sido abandonadas o domesticadas, apaciguadas por el crecimiento de las expresiones privadas de los deseos del consumidor. Las citas de activistas y militantes (Belotti y Codelesky entre ellas) sembradas entre los nombres de artistas y celebridades internacionalmente conocidas, nos transportan constantemente a mundos contrastantes. Dan origen a nuevas traducciones que promueven la crítica cultural a lugares en los que algunos sólo experimentan subordinación y pérdida. Por último, esta nómada y cambiante vivencia de la lengua sirve para ampliar los términos de referencia que marcan el cuerpo femenino.

Con respecto a esto, esta expansión de términos se nota con mayor fuerza en la constante presencia lesbiana que ingresa en la mirada editorial. Esto organiza una lectura de la cultura argentina, reconfigura el mapa Norte/Sur y obliga al lector a repensar los términos de la transmisión cultural. Los derechos sexuales, los intereses legales y la cotidianeidad compartida entre mujeres surgen como temas del suplemento, presentados ocasionalmente entre escenas de escándalos mediáticos, pero que siempre ofrecen la posibilidad de reflexiones alternativas acerca de la identidad femenina. Esta doble lectura está siempre presente en el proyecto de Moreno: revela que la elección sexual sirve tanto como cebo para una lectura escandalosa, como la oportunidad para afirmar la autonomía 
femenina. De este modo el suplemento se desliza hacia un campo sexual minado. Las editoras recurren a la escritora italiana Dacia Maraini, cuya obra teatral representada en Buenos Aires relata la atracción que experimenta la Condesa Bathory por seres de su mismo sexo; la obra sirve como pretexto para investigar las fantasías del público sobre el sexo lesbiano y el control del estado sobre la vida privada. Casos como éste muestran cómo una estética contemporánea depende de una erótica del mismo sexo, del mismo modo que la traducción al español del texto italiano de Maraini traslada el feminismo de una plataforma a otra, reclamando así nuevos vehículos a través de los cuales efectivizar la aparición pública de lo queer.

En este punto en nuestra historia intelectual es quizá un lugar común afirmar que lo queer reestructura nuestras categorías de conocimiento. Pero lo queer en las páginas de LAS/12 permite también a las escritoras libertad de movimiento; particularmente permite a las escritoras que colaboran cambiar el modo "antropológico" de abordaje y recurrir a los aspectos festivos de esta polémica cultural. En un significativo artículo sobre la marcha de gays y lesbianas de 1999 en Buenos Aires, María Moreno pone el discurso de las lesbianas en un lugar central como estrategia pública para cambiar el clima político de Argentina. Según Moreno, además de alertar al mundo sobre la cuestión de los derechos minoritarios, la marcha es profundamente festiva. De ahí nace su posibilidad de hacer política de una manera nueva. De hecho, sus aspectos no planeados expanden las posibilidades de inserción del sujeto en el espacio público. Desde una arqueología de los encuentros clandestinos y miradas furtivas a través del tiempo, Moreno traza una historia que tiene una resonancia pública más amplia, semejante al modo en que el relato de los logros políticos está siempre ligado a un estatuto carnavalesco: “¿acaso la toma del Palacio del Invierno, la entrada del Che en La Habana, la quema de corpiños de las militantes feministas que en Francia y EE.UU. exigían la legalización del aborto no fueron también fiestas?”, bromea con seriedad (“Lolas y besos”, 12 de noviembre, 1999). De lo que se trata es de ampliar los aspectos moderados de los discursos cerrados, de enfatizar el viaje y el movimiento, de hacer estallar la costura de lengua erudita y darle voz a los deseos polimorfos que pertenecen al masivo público lector. Esta multiplicidad combina conocimiento popular y de élite; más específicamente, nos obliga a pensar las formas en que los intereses de las mujeres se cruzan con otros sectores, también en la franja social. Teniendo esto en mente, no debe sorprendernos que $L A S / 12$ celebre el cruce de fronteras que realizan las mujeres en las procesiones carnavalescas o "murgas”. Diana Bellessi, la poeta argentina que Moreno cita al final de su artículo, de manera concisa da voz al proyecto:

Yo me considero de retaguardia, porque la retaguardia me liga a la parte de atrás de la murga adonde habitualmente van las mujeres que son la frontera entre la murga y el pueblo. Y siento que esa frontera es la auténtica vanguardia. (12 de noviembre de 1999)

Esta es, quizá, la clave de las estrategias que Moreno invoca en $L A S / 12$ y es un punto central para la demanda de la presencia lesbiana en la reorganización de las ideas en los medios masivos de comunicación: dar visibilidad a los vínculos que han sido suprimidos, conservar este enlace en el centro de atención del público, pero sobre todo, proclamar el 
lazo que existe entre las mujeres y las otras culturas marginales. Si el mercado autoriza el espectáculo, una presencia lesbiana, en el marco teórico de $L A S / 12$, ofrece un espectáculo en sí mismo, conectando los mundos Norte y Sur, enlazando el discurso masculino y femenino, alineando las posibilidades de diálogo entre la heterosexualidad y lo queer (la homosexualidad) en torno a la celebración común y la protesta pública. La presencia lesbiana en Página/12 obliga a lectores y editores a repensar las teorías de la cultura heteronormativa, amplía los términos de los escenarios de mercados masivos, pero también introduce la duda en un proyecto globalizado que es capaz de acallar o absorber las voces alternativas. Lo queer en estas páginas señala las deficiencias del periodismo en conjunto; le pide al lector que vuelva a la sección principal del diario y que considere los temas que no logran ingresar como "noticias". ¿Por qué será que género y sexualidad nunca logran la "primera plana" sino que, en vez de eso son relegados a la esfera menor del escándalo y lo suplementario? Si Página/12 controla el poder del relato, proveyendo historias para vender, el suplemento para mujeres nos dice de qué modo el género altera la experiencia de la confabulación.

A este respecto, podría decirse que $L A S / 12$ funciona por contradicción; desnaturaliza las corrientes normativas de significado que, en nuestros días, pasan sin problemas; altera aquellas estructuras de análisis establecidas por los medios y el mercado. Y, de hecho, si existe una "teoría" del feminismo que pueda derivarse de este tipo de escenarios, ésta se encuentra en el ataque que $L A S / 12$ lanza sobre las costumbres embotadas por la silenciosa sumisión de los consumidores. En este sentido, la venta de “autenticidad” o la representación de belleza "naturalizada" es examinada por la mirada editorial. Una vez más, las colaboradoras del suplemento para mujeres cubren temas que van desde la elección de una tintura para el cabello hasta la puesta en escena de imitaciones femeninas realizadas por travestis en los bares; pero los reclamos de autenticidad natural que Moreno y su equipo desentrañan también revela las limitaciones de una teoría que busca situar un tema de investigación y, finalmente, darle un nombre. Frente a esto, la máscara gana el interés de las escritoras; lo performativo queda a salvo ya que las escritoras ridiculizan todos los reclamos de un ser auténticamente femenino que haya sido traficado a través de la prensa dominante.

Reflexionando sobre el primer año de publicación, Sandra Russo señala:

Después fueron llegando, cada semana, otros temas en los que siempre e indefectiblemente la clave estuvo no sólo en diferenciar los intereses femeninos de los masculinos, sino además en abrir debate entre las mujeres, dando por sentado que esa entelequia que algunos llaman "la mujer" no existe. (30 de abril de 1999)

Más allá de la autorrepresentación se trata de construir una comunidad de alianzas. Así se continua en el mismo artículo:

En los grupos de mujeres consultados por las empresas Entrepreneur antes de la salida a la calle de $L A S / 12$ fue evidente que las consultas no reconocían en ninguno de los suplementos femeninos de los diarios nacionales rasgos de identificación o pertenencia como lectoras. "Lo miro pero no lo leo", "No trae nada que importe" o "Lo conozco pero no me acuerdo cómo es”, eran las respuestas típicas. En este año de vida, LAS/12 generó, 
a juzgar por el rebote que cada semana llega a la redacción a través de e-mails, cartas, llamados y comentarios, una complicidad que nos enorgullece, tanto de parte de mujeres como de varones. Que a quienes hacemos este suplemento nos encante hacerlo debe constituir, simple y cristalina, una clave de ésas que el marketing todavía no logró reemplazar ni sustituir. La sintonía entre lectoras/es y periodistas sigue siendo una alquimia bendita.

Es extraño que una comunidad pueda ser alcanzada y construida a través de los textos de los medios masivos, pero después de todo, quizá podamos preguntar, ¿cuál es el proyecto de la escritura política? Aquí, la cuestión de la subalternidad y de la alianza hace su camino fuera del campo académico, ampliando los antiguos parámetros del concepto de la amistad entre mujeres. Esto se observa en la celebración que LAS/12 hace de "Thelma y Louise”, en el valor que las editoras le otorgan a ciertos libros que relacionan a unas lectoras con otras; esto se demuestra en los análisis de las películas de Alfred Hitchcock u observando el papel de las mujeres en las óperas de Mozart; se ve también en la defensa de la militancia común o en la manera en que las mujeres se unen para desafiar la ley. Pero la amistad entre mujeres es también el lugar para otro tipo de posibilidad erótica:

¿Qué significa hoy la amistad entre mujeres? ¿Qué pueden tener en común las amigas que se encuentran a falta de algo mejor sin caer en la cuenta de que sus risas en común duran más de veinte minutos con las militantes apasionadas que quieren hacer una de dos? No se trata de "uniones homosexuales con instintos coartados en su fin”, como definía Freud al vínculo civilizador entre varones y que dio madera a la Iglesia y al Ejército. No es la pregunta por la propia femineidad la que lleva a las mujeres a las otras, tampoco la homosexualidad. Es aún un sentimiento sin nombre, de ahí el escándalo que suscita. No tiene aún historia como el de Fierro y Cruz, o el de Moreira y Julián. Es imposible blanquear de erotismo por el mero hecho de que no hace jugar la genitalidad, ni de reducir a un lesbianismo tasado por un heterosexualismo exhausto. A veces se parece a un amor que da vida una y otra vez sin que haya nadie colmado ni nadie exangüe, que podría asimilarse a una palabra también nueva: mismidad. Pero vale la pena recordar la frase de Santa Teresa de Jesús: "Importa tanto este amor de unas con otras, que nunca querría que se os olvidase”. (11 de junio de 1999)

Moreno exhibe los modos en que la ética masculina fija las categorías de la identidad del consumidor y los patrones del intercambio de productos, a la vez que demuestra, a pesar de sus reclamos liberales, la lógica autoritaria de las primeras décadas, que restringe el grado de alianza y pasión posibles dentro de cualquier orden social. En otras palabras, muestra cómo el poder de los medios masivos sirve a fines conservadores. La perspectiva feminista ingresa, por contraste, a través de gestos triviales de filtración, a través de conexiones establecidas en el movimiento Norte/Sur que sabotea los mercados establecidos, a través de conexiones sociales peligrosas entre mujeres y grupos marginales.

Para concluir, permítanme volver al problema de la traducción. Es obvio que las interrelaciones entre Norte/Sur, masculino y femenino, heterosexual y gay, suponen diferentes valores a través de los registros de traducción. En el tránsito de imágenes y textos, los problemas de traducción nos llevan a considerar los hábitos del coleccionista benjaminiano que reúne detalles dispares para un público siempre ávido. Capitalizando las 
demandas de los lectores que desean un abordaje bricolage de las ofertas globales de la cultura, el periodista, como un coleccionista, reordena los bienes descartables, traduciendo las imágenes a la lengua de los consumidores locales. Al tomar a las mujeres como objeto de estudio, LAS/12 muestra cómo éstas son permeables a proyectos de consumo en todo el mundo. También, $L A S / 12$ hace emerger la voz de las mujeres en un lugar que en otra parte de los medios ha sido silenciada. El trabajo de Moreno sobre las consecuencias del 11 de septiembre es ilustrativo. Su primer artículo después de esa fecha recuerda que el horror del ataque terrorista coincidió con la fecha planeada para discutir en la legislatura porteña la posible legalización de las uniones de gays y lesbianas en Argentina; un tema que fue aplazado a causa de los acontecimientos ocurridos en los Estados Unidos. En los números subsiguientes, Moreno continúa registrando cómo la solemnidad y el terror de los días que siguieron al ataque quedaron anotados por los testimonios de mujeres. Las respuestas de las mujeres en Nueva York consignan la importancia de los sentimientos inmediatos sobre el 11 de septiembre; la defensa de Bárbara Lee lleva a reflexionar sobre la posibilidad del disenso democrático; la pregunta acerca de los rostros velados por el dominio fundamentalista delata la situación ambigua de las mujeres como portavoces del cambio del orden mundial; las voces de los niños que hablan sobre el terror desmonta la teoría masculina. Todo esto forma parte del gesto de apertura de un espacio público para aquellas voces a menudo silenciadas.

Este continuo reconocimiento de otras voces y de estrategias alternativas de lectura sobre los hechos y fenómenos culturales de nuestro tiempo, se encuentra en el corazón de las lecturas ofrecidas en las páginas de $L A S / 12$. El suplemento también plantea una serie de problemas para futuros debates. En primer lugar, expone la tensión que existe entre la prosa expositiva perteneciente al periodismo masivo que adscribe a los grandes acontecimientos y la crítica de la sociedad basada en el género que cobra fuerza a través de una lectura del detalle "menor". A partir de esta doble lectura siempre presente en Página12 y el suplemento para la mujer, $L A S / 12$ desestabiliza todo aquello que avale un singular tema canónico y perturba el poder de las imágenes de consumo que asignan a las mujeres un papel social fijo. Esta experiencia sugiere un desplazamiento que una de las colaboradoras de $L A S / 12$ ha denominado “el arte de tentar y negar” (8 de octubre de 1999), un rumbo zigzagueante entre oferta y demanda, entre la propia capacidad crítica y la ceguera respecto de los efectos del mercado. En el proceso, LAS/12 crea un espacio para su propia y peculiar versión de su lectora ideal, ésa que es conciente de las múltiples identidades sexuales de que dispone el público femenino, ésa que conoce las contradicciones del deseo gobernado por el mercado mundial. Así, mientras Página/12 se ocupa de desmontar “el ser nacional”, el suplemento para mujeres da un paso más adelante al revelar el falso vínculo atribuido a las identidades marcadas genéricamente, cuya base se asienta en los funcionamientos del orden global y, finalmente, expone las imperfectas líneas que surcan la uniforme superficie del mapa Norte/Sur. En segundo lugar, el periodismo feminista del tipo que se produce en $L A S / 12$ desordena las categorías teóricas. Cuestiona el lugar de su propia invención y trata con descaro al régimen de mercado que defiende el diario en general. Confunde las lecturas de lo público y lo privado y trastorna los recorridos del discurso. Crea un lector que se erige entre la lógica institucional de la primera plana y un diseño de lo secundario que se ubica en el margen. En este proceso, LAS/12 propone 
una conexión entre la cultura oficial y la popular que nos obliga a prestar atención a los flujos e intersecciones del significado que puedan constituir sujetos genéricamente marcados. Sobre todo, el suplemento produce caminos alternativos de discontinuidad y convergencia; desbarata la ilusión de dominio propiciada por nuestra sensación de plenitud intelectual. Finalmente, nos recuerda la necesidad permanente de revisar la idea misma de suplementariedad, tanto en el cuerpo disponible para la escritura pública, como en aquel cuerpo privado que exprese la máxima amplitud posible de su deseo.

Traducción: Clara Klimovsky

\section{BiBLIOGRAFÍA}

Beauvoir, Simone de. El segundo sexo. Buenos Aires: Sudamericana, edición del 50 aniversario, 1999.

González Gaviola, Horacio y Marcelo Constantini. La realidad satírica: doce hipótesis sobre Página 12. Buenos Aires: Paradiso, 1992.

Moreno, María. El Petiso Orejudo. Buenos Aires: Planeta, 1994. El affair Skeffington. Rosario: Bajo la luna, 1992.

Sosnowski, Saúl y Jorge Aguilar Mora (Comp.). La cultura de un siglo: América Latina en sus revistas. Buenos Aires: Alianza Editorial, 1999. 